sodium $p$-toluene sulphinate containing 4 moles of water of crystallisation $(1.62 \mathrm{~g})$ were dissolved in $1 \mathrm{M}$ acetate buffer of $\mathrm{pH} 4.5(40 \mathrm{ml})$ and kept at $100^{\circ}$ for $3 \mathrm{~h}$. The mixture, which crystallised during the heating, was kept overnight at $0^{\circ}$ and the crystals $(0.94 \mathrm{~g})$, m.p. $169-172^{\circ}$, filtered off and washed with water.

(b) The same amounts of vanillyl alcohol and sodium $p$-toluene sulphinate were dissolved in $3 \mathrm{M}$ aqueous acetic acid $(40 \mathrm{ml})$ to which two drops of sulphuric acid were added. The mixture was kept at $100^{\circ}$ for $3 \mathrm{~h}$ and worked up as above, yielding the crystalline product $(1.72 \mathrm{~g})$, m.p. $171-175^{\circ}$.

Recrystallisations from ethanol or benzene yielded the pure substance, m.p. $175-176^{\circ}$. (Found: $\mathrm{OCH}_{3}$ 10.3; $\mathrm{S} 11.0 . \mathrm{C}_{15} \mathrm{H}_{16} \mathrm{O}_{4} \mathrm{~S}$ requires: $\mathrm{OCH}_{3}$ 10.6; S 11.0).

(3,4-Dimethoxyphenyl)-methyl p-tolylsulphone. Veratryl alcohol $(1.00 \mathrm{~g})$ and sodium $p$-toluene sulphinate ( $1.49 \mathrm{~g})$, treated as described in $(b)$ above, also yielded a sulphone $(1.10 \mathrm{~g})$, m.p. $176-177^{\circ}$ after crystallisation from ethanol. (Found: $\mathrm{OCH}_{3} 20.2 ; \mathrm{S} 10.4 . \mathrm{C}_{16} \mathrm{H}_{18} \mathrm{O}_{4} \mathrm{~S}$ requires: $\mathrm{OCH}_{3} 20.3 ; \mathrm{S} 10.5$ ).

1-(4-Hydroxy-3-methoxyphenyl)-ethyl p-tolylsulphone. The alcohol (apocynol, III) was prepared by borohydride reduction of (4-hydroxy-3-methoxy)-acetophenone, essentially as described by Adler and Hernestam 4. A large excess of borohydride was maintained during the whole reaction by adding fresh amounts of borohydride to the system at intervals.

Apocynobl $(0.20 \mathrm{~g})$, sodium $p$-toluene sulphinate $(0.33 \mathrm{~g})$ and a drop of sulphuric acid were dissolved in a mixture of ethanol $(3 \mathrm{ml})$ and $3 \mathrm{M}$ acetic acid $(5 \mathrm{ml})$ and the mixture kept on the steam bath for $3 \mathrm{~h}$. The oily product which separated during the reaction, crystallised on cooling $(0.35 \mathrm{~g})$ and after crystallisation from ethanol afforded the pure sulphone $(0.31 \mathrm{~g})$, m.p. $119-121^{\circ}$. (Found: $\mathrm{OCH}_{3} 9.8 ; \mathrm{S} 10.5 . \mathrm{C}_{16} \mathrm{H}_{18} \mathrm{O}_{4} \mathrm{~S}$ requires: $\mathrm{OCH}_{3}$ $10.1 ; \mathrm{S} 10.5)$.

1-(3,4-Dimethoxyphenyl)-ethyl p-tolylsulphone. 1-(3,4-Dimethoxyphenyl)-ethanol $(0.24 \mathrm{~g})$ and one drop of sulphuric acid were added to a mixture of $3 \mathrm{M}$ acetic acid $(5 \mathrm{ml})$ and ethanol $(1 \mathrm{ml})$ which was then heated on the steam bath for $3 \mathrm{~h}$ and worked up as above, yielding the sulphone $(0.33 \mathrm{~g})$. The product, after crystallisation from ethanol and benzene, melted at $124-126^{\circ}$. (Found: $\mathrm{OCH}_{3}$ 19.2; $\mathrm{S}$ 9.8. $\mathrm{C}_{17} \mathrm{H}_{20} \mathrm{O}_{4} \mathrm{~S}$ requires: $\mathrm{OCH}_{3}$ 19.4; S 10.0).

Acta Chem. Scand. 17 (1963) No. 5
1. Hinsberg, O. Ber. 50 (1917) 468.

2. Balfe, M. P., Kenyon, J. and Thain, E. M. J. Chem. Soc. 1952790.

3. Davies, A. G., Edwin, E. E., Kenyon, J. and Walsh, A. J. Chem. Soc. 19573158.

4. Adler, E. and Hernestam, S. Acta Chem. Scand. 9 (1955) 319.

Received May 8, 1963.

\section{The Supposed Existence of two Molecular Forms in Crystals of Acetyl Choline Bromide}

\author{
J. D. D U N I T Z
}

Organic Chemistry Laboratory, Swiss Federal Institute of Technology, Zürich, Switzerland

X-Ray diffraction data from crystals of Aacetyl choline bromide have been interpreted in terms of a monoclinic unit cell $a=11.10 \AA, b=13.67 \AA, c=7.18 \AA$, $\beta=110.0^{\circ}$, space group $P 2_{1}$, containing 4 molecules, and a structure has been proposed in which the two acetyl choline ions in the asymmetric unit occur as distinct conformational isomers ${ }^{1}$. The analysis, however, was complicated by the presence in the X-ray photographs of weak, subsidiary reflexions that are not accounted for by the proposed structure.

The main features of these extra reflexions have been described ${ }^{2}$ as follows:

(1) $h 0 l$ reflexions with $h$ odd are absent but subsidiary reflexions occur slightly displaced from these points.

(2) $h 0 l$ reflexions with $h$ even, $l$ even have subsidiary reflexions; those with $h$ even, $l$ odd do not.

(3) $h k l$ reflexions have subsidiary reflexions for all values of $h$ und $l$.

(4) $h k 0$ reflexions are not accompanied by subsidiary reflexions.

It was also mentioned (i) that the displacement of the subsidiary reflexions from the ideal reciprocal lattice points decreases towards $h k 0$, and (ii) that the subsidiary reflexions occur on only one side of the principal reflexions.

The purpose of the present communication is to point out that all these and other features of the subsidiary reflexions can be simply accounted for if it is assumed that the space group is not $P 2_{1}$ but $P 2_{1} / a$ and that the crystals are twinned across the $(10 \overline{2})$ plane. Since $2 c^{*} \cos \beta^{*} / a^{*}$ is nearly equal to unity (1.057) the $h k l$ re- 
flexion from the twin will nearly coincide with the $-(h+l) k l$ reflexion from the main crystal and will appear as a satellite, displaced by $0.057 l a^{*}$ from the main reflexion. The apparent "absences" follow from the space group absences. This interpretation accounts successfully not only for the positions but also for the intensities of the observed subsidiary reflexions ${ }^{3}$.

The arguments for the existence of two distinct molecular forms in the crystal are seriously weakened by rejecting the space group $P 2_{1}$ in favour of $P 2_{1} / a$. In the higher space group, the 4 molecules in the unit cell are symmetry related and hence identical or enantiomorphic, at least in a statistical sense. The existence of two distinct forms is only possible if the crystal structure is disordered, and there seems to be no compelling evidence for this.

Dr. Sörum has informed me that he agrees with my interpretation of the subsidiary reflexions, and has undertaken to re-examine the crystal structure. I am grateful to him for helpful correspondence concerning this problem.

1. Sörum, H. Acta Chem. Scand. 13 (1959) 345.

2. Sörum, H. Acta Chem. Scand. 10 (1956) 1669.

3. Sörum, H. Private communication.

Received April 30, 1963.

\section{The Stability of 1,1-Dibromo- acetone \\ CHRISTOFFER RAPPE}

Institute of Chemistry, University of Uppsala, Uppsala, Sweden

1,1-Dibromoacetone can be prepared according to Hughes, Watson and Yates in about $30 \%$ yield by bromination of bromoacetone ${ }^{1}$. It is found that a sample of this compound kept at room temperature undergoes rearrangement, while a sample kept in the dark in a refrigerator for 2 months is only little affected.
Rearranged samples were analyzed by NMR-techniques and the following compounds identified: monobromoacetone, 1,1 dibromoacetone, 1,3-dibromoacetone and 1,1,3-tribromoacetone. The relative a. mounts of the different products were determined.

Two samples were studied. One sample (A) was kept in a light place for $\mathbf{5 0}$ days and the percentages of the different products found are given in Table 1 .

In order to ascertain if the rearrangement was catalyzed by light, a sample of 1,1-dibromoacetone (B) was kept in the dark at room temperature for 13 and for 20 days. The compositions after these times were determined and are given in Table 1.

The occurrence of monobromoacetone and 1,1,3-tribromoacetone indicates that the rearrangement is intermolecular, but no details of the mechanism are known. Bromoketones are known to undergo a halogen rearrangement, and in these examples the rearrangements were found to be catalyzed by free hydrogen bromide; see Ref. ${ }^{2}$ where references are collected.

It is interesting to note that the rearrangement of 1,1-dibromoacetone gives products with one more and one less bromine atom, as in the rearrangement of 3 -bromo-to 5-bromolaevulic acid.

Although no equilibrium is reached and the results are preliminary, one can notice that the main product of the rearrange. ment is the symmetrical dibromoketone. The amount of monobromoacetone appears to be constant during the procedure.

The author has started to study this rearrangement in more detail, particularly with regard to its mechanism and kinetics, and the results will be published elsewhere.

Acknorledgements. The author wishes to express his thanks to Professor Arne Fredga for his interest in this work and for all facilities put, at his disposal.

1. Hughes, E. D., Watson, H. B. and Yates, E. D. J. Chem. Soc. 19313318.

2. Rappe, C. Arkiv Kemi 20 (1962) 51.

Received May 8, 1963.

Table 1.

Sample A (50 days)

Sample B (13 days)

Sample B (20 days)

\section{$\mathrm{CH}_{3} \mathrm{COCHBr}_{2}$}

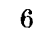

42

33

\section{$\mathrm{CH}_{3} \mathrm{COCH}_{2} \mathrm{Br}$}

21

18

21

$\mathrm{CH}_{2} \mathrm{BrCOCH}_{2} \mathrm{Br}$
68
26
33

$\mathrm{CH}_{2} \mathrm{BrCOCHBr}_{2}$ 33
14

Acta Chem. Scand. 17 (1963) No. 5 